\title{
Synthetic Melanin Films as Potential Interfaces for Peroxynitrite Detection and Quantification
}

\author{
Haitham F. Kalil \\ Cleveland State University, h.kalil@csuohio.edu \\ Shaimaa Mahera \\ Cleveland State University \\ Tiyash Bosed \\ Cleveland State University \\ Ousama Al-Mahmoude \\ Cleveland State University \\ Clara Kay \\ Cleveland State University
}

See next page for additional authors

Follow this and additional works at: https://engagedscholarship.csuohio.edu/scichem_facpub

Part of the Chemistry Commons

How does access to this work benefit you? Let us know!

Publisher's Statement

Copyright (C)The Electrochemical Society

\section{Recommended Citation}

Kalil, H.; Maher, S.; Bose, T.; Al-Mahmoud, O.; Kay, C.; Bayachou, M., Synthetic Melanin Films as Potential Interfaces for Peroxynitrite Detection and Quantification. ECS Transactions 2017, 80 (10), 1447-1458.

This Article is brought to you for free and open access by the Chemistry Department at EngagedScholarship@CSU. It has been accepted for inclusion in Chemistry Faculty Publications by an authorized administrator of EngagedScholarship@CSU. For more information, please contact library.es@csuohio.edu. 


\section{Authors}

Haitham F. Kalil, Shaimaa Mahera, Tiyash Bosed, Ousama Al-Mahmoude, Clara Kay, and Mekki Bayachou 


\title{
Synthetic Melanin Films as Potential Interfaces for Peroxynitrite Detection and Quantification
}

\author{
H. Kalil, S. Maher, T. Bose, O. Al-Mahmoud, C. Kay, and M. Bayachou
}

Peroxynitrite (PON) is a highly reactive oxygen-nitrogen species that facilitates both oxidation and nitration reactions. Early reports have revealed the deleterious effects of PON on DNA, proteins, and lipids. Recent studies have suggested that melanin can act as an antioxidative therapy to scavenge the reactive oxygen-nitrogen species (RO-NS) including PON. Melanin is a natural pigment that has many physiological functions involving the neutralization of highly oxidative species. In this project, the interaction between PON and synthetic melanin has been studied. In addition, the electrochemical characteristics of the polymerized 5,6-dihydroxy indole (DHI) as a model of synthetic melanin were examined using cyclic voltammetry and electrochemical quartz crystal microbalance (EQCM). The ultraviolet-visible (UV-Vis) spectroscopy showed a significant difference in the absorbance of PON alone and in the presence of melanin films. Finally, we report on the possibility of using the DHI-melanin film as a platform for the quantitative detection of PON in solutions.

\section{Introduction}

Melanin is a biological polymer found primarily in the surfaces of many organisms (1-2). In humans, it is found in the hair, skin, eyes, and also in the nervous system (3). Melanin pigment is the product of a group of cells known as melanocytes, which are mainly found in the epidermis and hair follicles (4-5). Melanin can also be produced by other cells in the body such as retinal pigment epithelium (RPE), epithelia of iris and ciliary body of the eye, certain neurons, and adipocytes (5-6). The pigments provide several useful functions throughout the body including determination of skin and eye color, as well as photoprotection of skin by absorbing and scattering harmful ultraviolet rays (1). The melanin pigments also protect against the damages caused by lipofuscin accumulation in the RPE, cytotoxic molecules, and transduction of energy (4). There are three types of melanin that can be found: eumelanin, pheomelanin, and neuromelanin (7). The most common type of melanin is eumelanin, which gives the brown-black pigment to hair, skin, and eyes (8). Pheomelanin provides a red-pink pigment and is common in red-haired people. Neuromelanin is a dark pigment located in the brain and other parts of the nervous system (9). 
Melanin is produced inside melanosomes by melanocytes that contain tyrosine moieties. Tyrosine undergoes a series of oxidative reactions to produce 5,6-dihydroxyindole (DHI), which is a precursor of natural melanin (10). DHI can be synthesized in a laboratory via the hydrolysis of 5,6-diacetoxyindole (DAI). Once DHI is synthesized, it is autoxidized to form quinone, which is the building block of melanin. The ideal oxidation of DHI can be performed by using an oxidizing agent or by electro-polymerization technique, where a positive potential is applied. Eumelanin is a polymer that consists of DHI, 3,4-dihydroxyphenethylamine (DOPA), and 5,6dihydroxyindole-2-carboxylic acid (DHICA) derivatives, while pheomelanin consists of sulfur containing benzothiazine derivatives (11).

Free radicals and RO-NS can interact with the organelles in vivo or with other molecules causing an oxidative damage and evolving into a wide range of health problems, such as cancers and cardiovascular diseases (11). The role of antioxidants is to counteract the reactivity of the free radicals and other reactive species by scavenging radicals, donating hydrogen and electrons, decomposing peroxide, quenching singlet oxygen, and/or inhibiting enzymes (4). Melanin is an example of a natural antioxidant, that is used to scavenge radicals and neutralize PON (8).

Peroxynitrite ( $\mathrm{PON}, \mathrm{ONOO}^{-}$) is a powerful oxidizing agent that belongs to the family of RONS. PON is formed by the reaction of nitric oxide (NO) and superoxide radical-anion $\left(\mathrm{O}_{2}{ }^{-}\right)$. It is a potent oxidative and nitrosative agent that has a variety of deleterious and cytotoxic effects in cells and tissues. Clinical reports have shown the noxious effects of this metabolite on the cellular level, ranging from damaging DNA and the lipids of cell membranes to inflammation and reduced cardiac muscle contractions. PON is also involved in several ailments such as neurodegenerative disorders, inflammations, diabetes, cancers, and cardiovascular diseases (12-13). Recently, PON has been added as a new member of the nitroxidative array of reactive metabolites (13).

Early reports have been conducted to examine the effects of melanin against reactive oxidants $(1,4,7)$. In 2005, Norris et al. studied RPE melanin radicals scavenging activities for photogenerated ROS under aerobic and anaerobic conditions (4). Norris and his colleagues have concluded that melanin exist in both the extrinsic and intrinsic populations of RPE cells, allowing melanin to protect the RPE against toxic species in both the light and dark conditions (4). In another study, Akeo et al. worked on determining whether melanin granules affect the oxidation of LDOPA and the generation of NO and $\mathrm{O}_{2}^{--}$in bovine RPE cells (6). It has been found that the quantity of NO produced was dependent on the concentration of L-DOPA and that the NO production was inhibited by the presence of melanotic RPE cells.

Several studies have focused specifically on the impact of neuromelanin and PON in the brain (14-16). A study by Padamaja and Madison was established to examine the reaction between PON and melanin precursor DHICA (17). The research found that PON rapidly oxidizes DHICA to form indole-5,6-quinone-2-carboxylic acid (DHICA-Q), which continues with further oxidation to form melanin-like polymer. In a different study, Stepien et al. investigated the effects of synthetic neuromelanin on peroxynitrite-induced tyrosine nitration and linoleic acid (15). The conclusion of this study was that melanin can act as a natural scavenger of PON, the latter acts as a mediator of the neurotoxic processes associated with Parkinson's disease. The findings suggest that the protection by neuromelanin is physiologically significant in defending against PON. In a similar study by Shi et al., the researchers had explored developing bio-inspired melanin nanoparticles as 
a novel nano-antioxidative therapy of ischemic brain injury $(6,18-19)$. Their results showed that some antioxidants have revealed specific scavenging activities against specific RO-NS, such as peroxides.

Herein, we have investigated the interaction between PON and the synthetic DHI-melanin films, which formed by the electro-polymerization of the DHI molecules on glassy carbon electrodes (GCEs) or indium tin oxide (ITOs) glass substrates. The investigation was carried out by exposing the polymerized-film to authentic PON in solutions and monitor the change using cyclic voltammetry. Further analyses to the melanin films were done to analyze the characteristics of the product, which include UV-Vis, QCM, and SEM.

\section{Experimental Section}

\section{Preparation of Phosphate Buffer Solution}

Potassium phosphate monobasic (4.209 $\mathrm{g}$ ) and potassium phosphate dibasic (3.322 $\mathrm{g})$ salts were dissolved in $1 \mathrm{~L}$ of a deionized water to make a phosphate buffer solution $(0.05 \mathrm{M})$. A few drops of $\mathrm{HCl}$ or $\mathrm{NaOH}$ was added as necessary to adjust the $\mathrm{pH}$ of the prepared buffer solution at 7.4.

\section{Synthesis of Peroxynitrite}

Peroxynitrite was synthesized by a two-phase displacement reaction between isoamyl nitrite and hydroperoxide anion, which form the organic and the aqueous phases respectively (20-21). A volume of $23 \mathrm{~mL}$ of hydrogen peroxide solution in a round flask placed in an ice bath and then 5 $\mathrm{mL}$ of sodium hydroxide $(5 \mathrm{~N})$ was added to the flask. Furthermore, a solution of DTPA $(0.04 \mathrm{M})$ in $5 \mathrm{~mL}$ sodium hydroxide $(0.05 \mathrm{~N})$ was poured into the reaction mixture. The total volume of the solution in the round flask was increased by dilution to $100 \mathrm{~mL}$ with deionized water, thus dilution brings the concentration of hydroperoxide anion to $0.2 \mathrm{M}$. The final step of the synthesis of PON was to mix $27 \mathrm{~mL}$ of isoamyl nitrite $(0.2 \mathrm{M})$ with the solution in the round flask and stir the whole mixture vigorously in an ice bath for five hours, in which peroxynitrite is released into the aqueous layer. Peroxynitrite was purified from the reaction vessel and characterized by UV/Vis spectrometry. Finally, the purified peroxynitrite was aliquoted into a one $\mathrm{mL}$ Eppendorf vials and sealed before keeping in the freezer at $-80^{\circ} \mathrm{C}$.

\section{Polishing of the Glassy Carbon Electrodes}

To restore the electrode's surface, GCEs were rinsed thoroughly with deionized water and polished on two different polishing pads with alumina polishing powder, sizes 0.3 and 0.05 micron respectively. While polishing, the surfaces of the electrodes were rubbed in a circular motion for about 12 cycles, perpendicular on the polishing pads. Once finished, the electrodes were rinsed again carefully with deionized water and they were dried under a continues nitrogen air stream. 


\section{Electro-polymerization of DHI-Melanin Film}

All steps of melanin film formation were performed using air-tight apparatus under a constant nitrogen atmosphere to avoid spontaneous oxidation of the melanin precursor solution. A volume of $12.5 \mathrm{~mL}$ ethanol was degassed for 15 minutes with nitrogen gas prior to be added to a $3.0 \mathrm{mg}$ of DAI ( $0.001 \mathrm{M}, 12.5$ mmoles). In addition, a two-mole equivalent of $0.25 \mathrm{~mL} \mathrm{NaOH}(0.1 \mathrm{M}, 25$ mmoles) was added to deacetylate the DAI molecules and yield the DHI. The solution was allowed to stand for 15 to 20 minutes before diluting with $25 \mathrm{~mL}$ of degassed phosphate buffer solution (0.05 M, pH 7.4). For DHI-melanin electro-polymerization, a cyclic voltammetry technique was performed on GCEs for 20 cycles with a potential sweep from 0.40 to $-1 \mathrm{~V}$ versus $\mathrm{Ag} / \mathrm{AgCl}$ reference electrode at a scan rate of $0.05 \mathrm{~V} / \mathrm{s}$. Similar steps were used for electro-polymerization of DHI on ITO glass-based electrodes. In contrarily from other melanin film preparation methods, no autoxidation of DHI-melanin was formed in the bulk of solution as assessed by the transparency of the solution during all steps of melanin formation.

\section{Electrochemical Measurements and Spectroscopic Analysis}

The electrochemical analysis of the prepared DHI-melanin films was performed using CHI1030B Multi-Mode Potentiostat workstation. Cyclic voltammetry measurements were carried out in electrochemical cell, which contains GCE or ITO as a working electrode, $\mathrm{Ag} / \mathrm{AgCl}$ electrode as a reference electrode, and platinum wire as auxiliary electrode. Moreover, the thickness of DHImelanin film was calculated using the obtained data from EQCM. In this technique, a quartz crystal covered with gold metal is acting like a working electrode, while the reference and auxiliary electrodes are the same as used in voltammetry method. The Sauerbrey equation [1] is used to calculate mass/area $(\Gamma)$ of the electro-polymerized DHI-melanin film (22):

$$
\begin{aligned}
& \Gamma=-C \times\left(\Delta f_{v} / v\right) \\
& d=\Gamma / \rho
\end{aligned}
$$

where the value of the constant proportionality $(\mathrm{C})$ is given by the quartz crystal and the frequency is measured as a function of time using the oscillator. Moving forward, from equation [2], the thickness (d) can be simply determined by dividing $\Gamma$ on the density $(\rho)$ of melanin $(\rho=1.2 \pm 0.1$ g.cm ${ }^{-2}$, which was previously calculated (23-24)).

An Accumet AB15 pH-meter was used for $\mathrm{pH}$ measurements. SEM analyses were carried out using a Hitachi S-4500 Field Emission Gun Scanning Electron Microscope (FESEM). UV-Visible absorbance spectral studies were recorded on an Agilent 8453 spectrophotometer using a $1 \mathrm{~cm}$ path length quartz cuvette, where two cuvettes were filled with $3 \mathrm{~mL}$ of phosphate buffer $(\mathrm{pH} \mathrm{7.4)} \mathrm{at}$ room temperature. A blank absorbance measurement was taken for each of them. Then, $10 \mu \mathrm{L}$ of peroxynitrite was added to each of the cuvettes, and the initial absorbance measurement was taken after ten minutes of the addition. At this point, $10 \mu \mathrm{L}$ of sodium hydroxide $(10 \%)$ was added to one of them (control), and on the other cuvette, $10 \mu \mathrm{L}$ melanin film (dissolved in $10 \% \mathrm{NaOH}$ ) was added (sample). Five absorbance measurements were taken after ten minutes of each addition. 


\section{Result and Discussion}

Melanin is a ubiquitous natural pigment, which forms from the oxidation of tyrosine and its derivatives (24-27). The synthetic eumelanin is formed by the deacetylation of DAI to produce the corresponding quinone form (DHI intermediate). The formed intermediate is highly reactive and can be easily oxidized to the polymeric eumelanic structure via the radical-coupling reaction. Hydrolysis process was achieved by dissolving the DAI in ethanol, then adding a two mole equivalent of $\mathrm{NaOH}$. Under perfect conditions the solution should be clear and colorless, but when it is exposed to oxygen it turns quickly to pink or dark purple due to DHI autoxidation mechanism (28-32). Therefore, the adhesion and thickness of synthetic melanin film is based on the transparency and the number of moles of DHI monomers in the solution mixture.

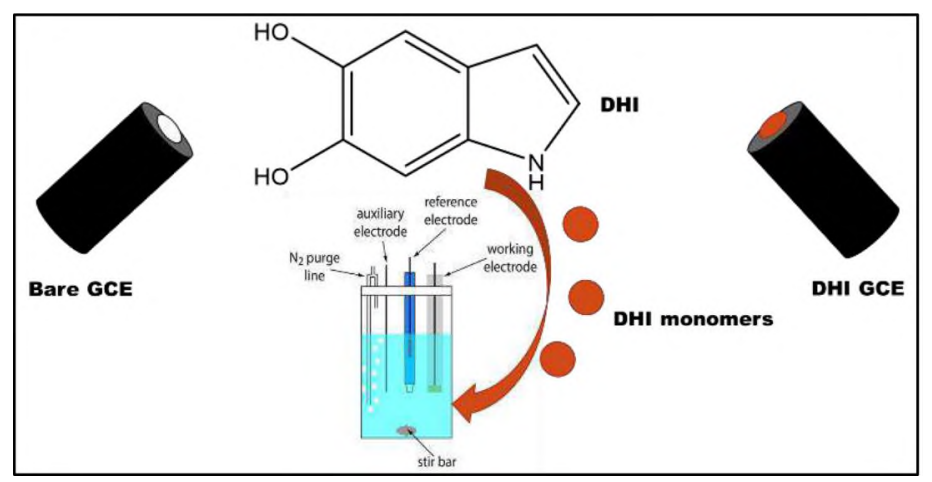

Scheme 1. Schematic diagram of DHI-melanin film electro-polymerization

A typical cyclic voltammogram of DHI polymerization is shown in Fig. 1 and illustrated in Scheme-1. Four main peaks can be seen in the figure: two broad cathodic peaks in the region from -1 to $-5 \mathrm{~V}$, a weak anodic peak around $-2 \mathrm{~V}$, and another strong oxidation anodic peak at $+0.02 \mathrm{~V}$. These characteristic peaks elucidate the electro-polymerization of DHI monomers and the formation of a growing conductive thin film of melanin polymer. The first anodic peak (A) at $+0.02 \mathrm{~V}$ is assigned for the oxidation of DHI to a semiquinone through one electron transfer reaction, while the second anodic peak $(B)$ of the second cycle is attributed to the oxidation of semiquinone to quinone, which triggers the polymerization initiation reaction of DHI-melanin. By adding more cycles using cyclic voltammetry, we practically are adding more layers of synthetic melanin films. It has been found that twenty cycles are the optimum number of voltammetric cycles to get a uniform polymeric melanin film with thickness range from 20 to $30 \mathrm{~nm}$. Cycling the potential between -1 to $+0.4 \mathrm{~V}$ vs. $\mathrm{Ag} / \mathrm{AgCl}$ shows steady current increase, which indicates the growth of DHI polymeric structures on the electrode surface. It is worth noting that the thick DHImelanin film that might be obtained by either raising the concentration of DAI or increasing the cycles of cyclic voltammetry has low adhesion properties. The thicker melanin film peels off easily from the substrate surfaces by scrub test or immersing in ethanol or $10 \% \mathrm{NaOH}(\mathrm{pH} 10.5)$. After several trials, we found that the optimum concentration of DAI is $1 \mathrm{mM}$ that has been hydrolyzed to give the same concentration of melanin precursor DHI. 

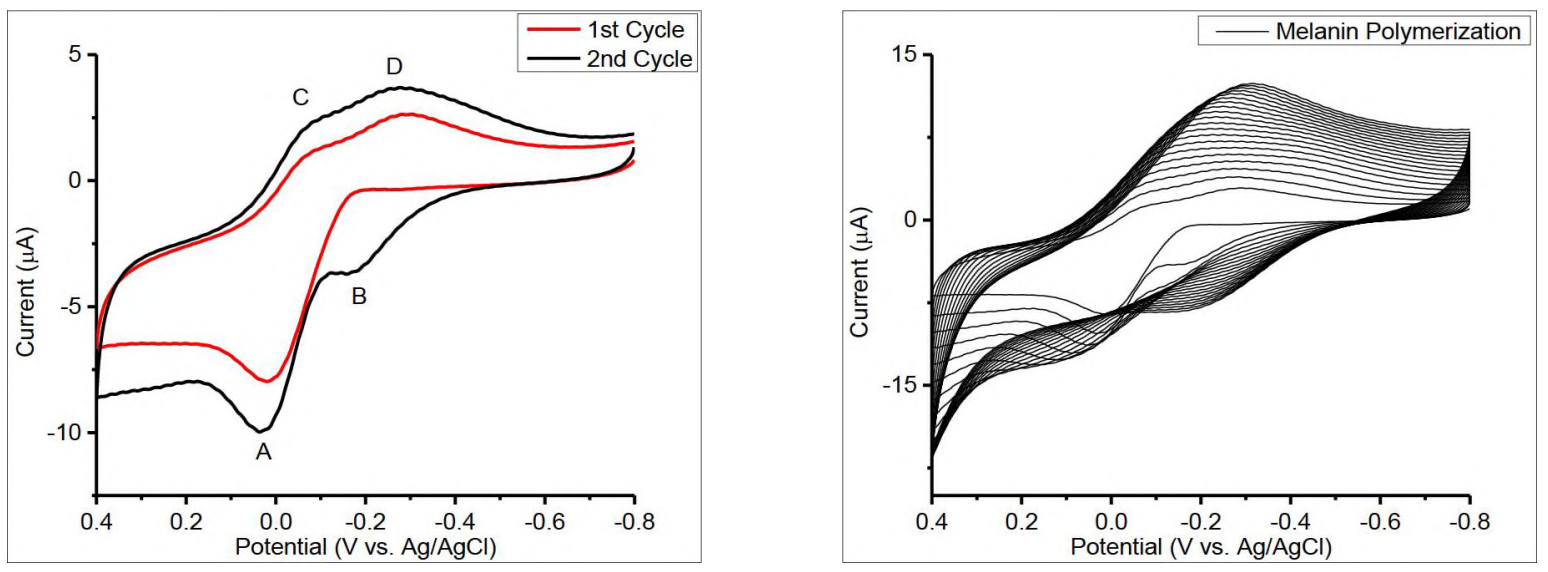

Figure 1. Cyclic voltammograms of electrodeposition of $1 \mathrm{mM}$ DHI monomers solution on glassy carbon electrode in phosphate buffer $\mathrm{pH}=7.4$ at scan rate of $0.05 \mathrm{~V} / \mathrm{s}$ for 20 cycles

Several experimental procedures have been established to propose the mechanism of DHImelanin formation (28-32). Interestingly, those methods are sharing the same concept of melanin formation through the radical chain polymerization reaction. As described in Scheme-2, hydroquinone form (DHI) undergoes oxidation reaction by applying positive current and, therefore, it losses one electron to give semiquinone, which returns back to hydroquinone by applying negative potential. More likely, the semiquinone suffers more oxidation to give the unstable quinone form that shows equilibrium with the quinone-imine form and finally polymerizes to eumelanin.

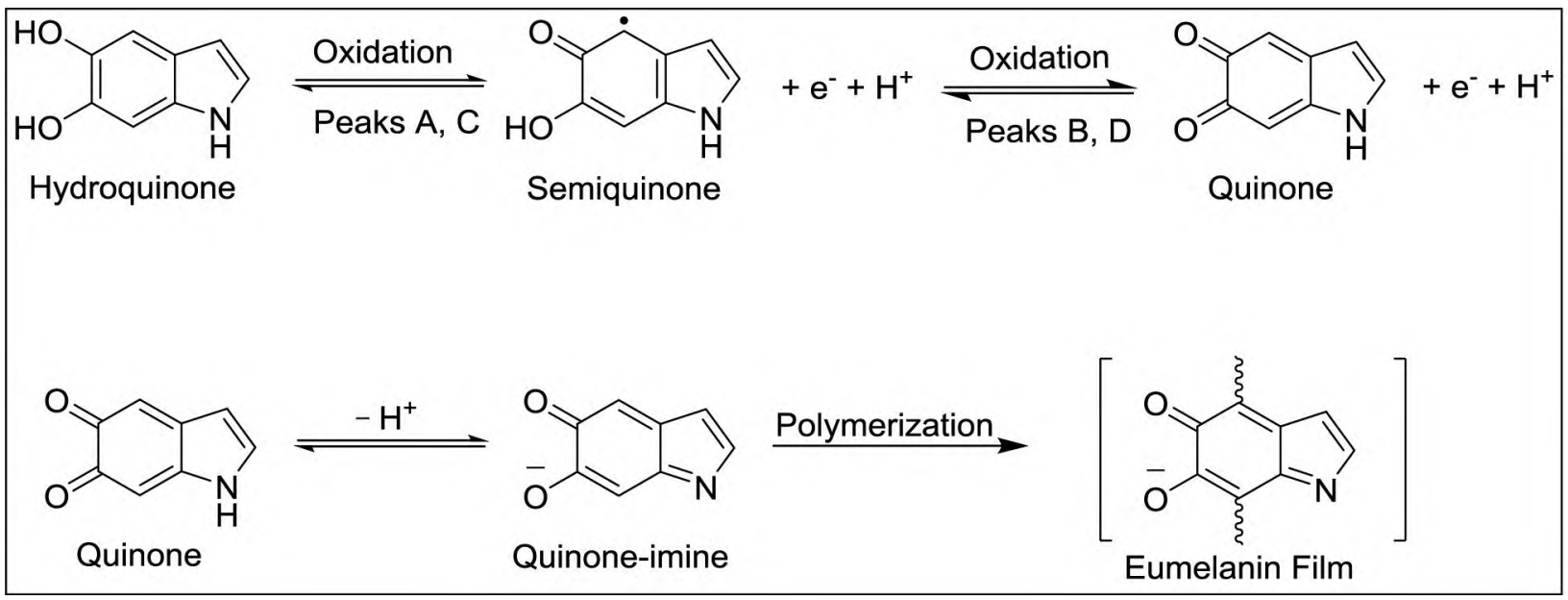

Scheme 2. Postulated mechanism of DHI-melanin film formation 
One of the main aspects of DHI-melanin film surface characterization was SEM. As shown in Fig. 2, the morphology of the melanin film is depicted with two SEM-micrographs at two different magnifications. The first micrograph on the left at $5 \mu \mathrm{m}$ illustrates the uniformed feature of melanin film with multilayers stacked together without more details. However, the DHI-melanin nanoparticles can be normally seen under high magnification at $500 \mathrm{~nm}$ as semi-spherical nanoparticles structures with $\sim 100 \mathrm{~nm}$ size (right micrograph). Our SEM images are compatible with previously published data of melanin nanoparticles micrographs (33). The only difference between the synthetic melanin and the natural melanin is the shape because the natural melanin has ball-shape nanostructured film with an average size of $\sim 95 \mathrm{~nm}$.
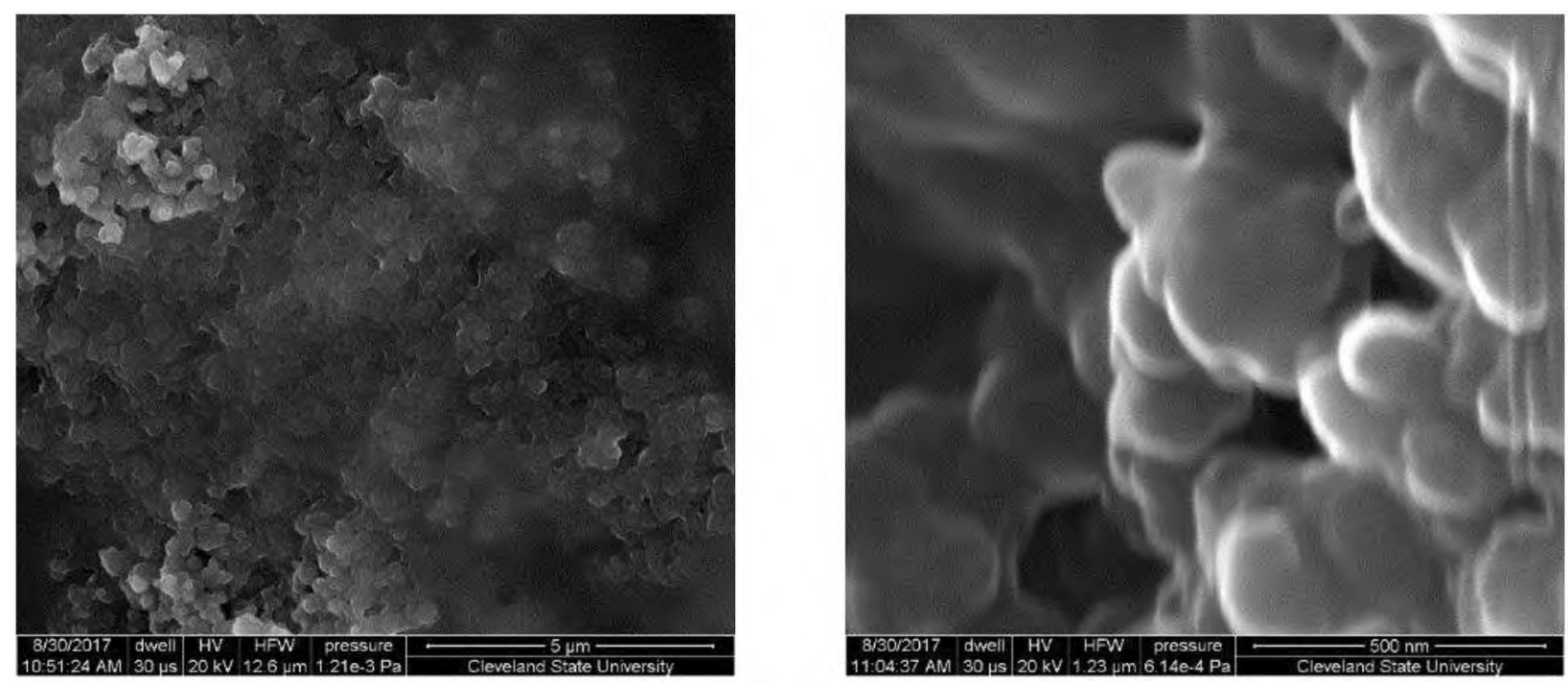

Figure 2. SEM micrographs of the prepared DHI-melanin films at different magnifications

Various attempts have been reported to electro-polymerize dopamine or DHI using the cyclic voltammetry electrochemical deposition (28-32). One of the most important aspects of the electrochemically synthesized melanin films from DHI precursors is the buffer solution, which acts as an electrolyte and maintains the $\mathrm{pH}$ of the reaction mixture. Although the most prepared melanin films in the PBS (pH 7.4) are suffering weak adhesion on the substrate of working electrodes when the thickness of the synthetic melanin films exceed certain micrometers, our prepared DHI-melanin films have a good adhesion toward the electrode substrates. We found that the optimum thickness should be between 20 to $30 \mathrm{~nm}$ to prevent an easily peeling off from the substrates when the film is immersed in alcohol or $10 \% \mathrm{NaOH}(\mathrm{pH} 10.5)$. 

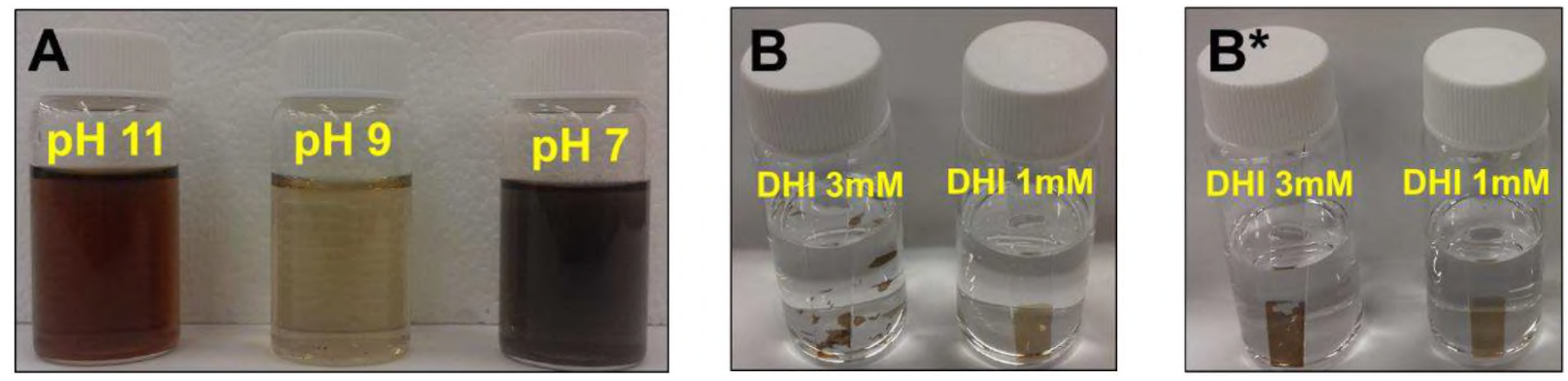

Figure 3. Photographs of (A) melanin nanoparticles solutions at different pHs (B) melanin films deposited on TIOs in $\mathrm{NaOH} \mathrm{pH}=10.5\left(\mathrm{~B}^{*}\right)$ in $\mathrm{EtOH}$

As shown in Fig. 3 (A), the melanin films have been collected and dispersed in deionized water $(\mathrm{pH} 7$ ), and then a few drops of $\mathrm{NaOH}$ concentrated solution were used to rise the $\mathrm{pH}$ to 9 and 11 . It has been well observed that the black melanin dispersed particles in deionized water have no change at $\mathrm{pH}=7$, while the color and solubility of the dispersed melanin films were changed and increased by raising the $\mathrm{pH}$ to 9 (straw yellow color) and finally to $\mathrm{pH}=11$ to form a clear dissolved brown melanin solution. On the other hand, in Fig. 3 (B \& $\mathrm{B}^{*}$ ), the melanin films at two different concentrations coated ITO glass substrates have been immersed in $10 \% \mathrm{NaOH}(\mathrm{pH} 10.5)$ and alcohol, which left for $24 \mathrm{hrs}$ to check the adhesion properties of the film to its substrate. It has been found that the melanin film that has been prepared using $3 \mathrm{mM}$ of DHI displaying high degree of peeling off when exposed to $\mathrm{NaOH}$, whereas it shows some resistance in ethanol. On contrast, the melanin films that were formed using $1 \mathrm{mM}$ of DHI have been showing excellent adhesion properties against the ITOs substrates in both $\mathrm{NaOH}$ and ethanol solvents. These observations refer to the possibility to dissolve the DHI-melanin film at high $\mathrm{pHs}$ like $\mathrm{NaOH}(\mathrm{pH} \mathrm{11})$. In addition, the DHI-melanin films that are formed from lower concentrations of DHI (1 mM) and immersed in ethanol or $\mathrm{NaOH}$, demonstrate a better adhesion than using the higher concentration of DHI precursor $(3 \mathrm{mM})$.
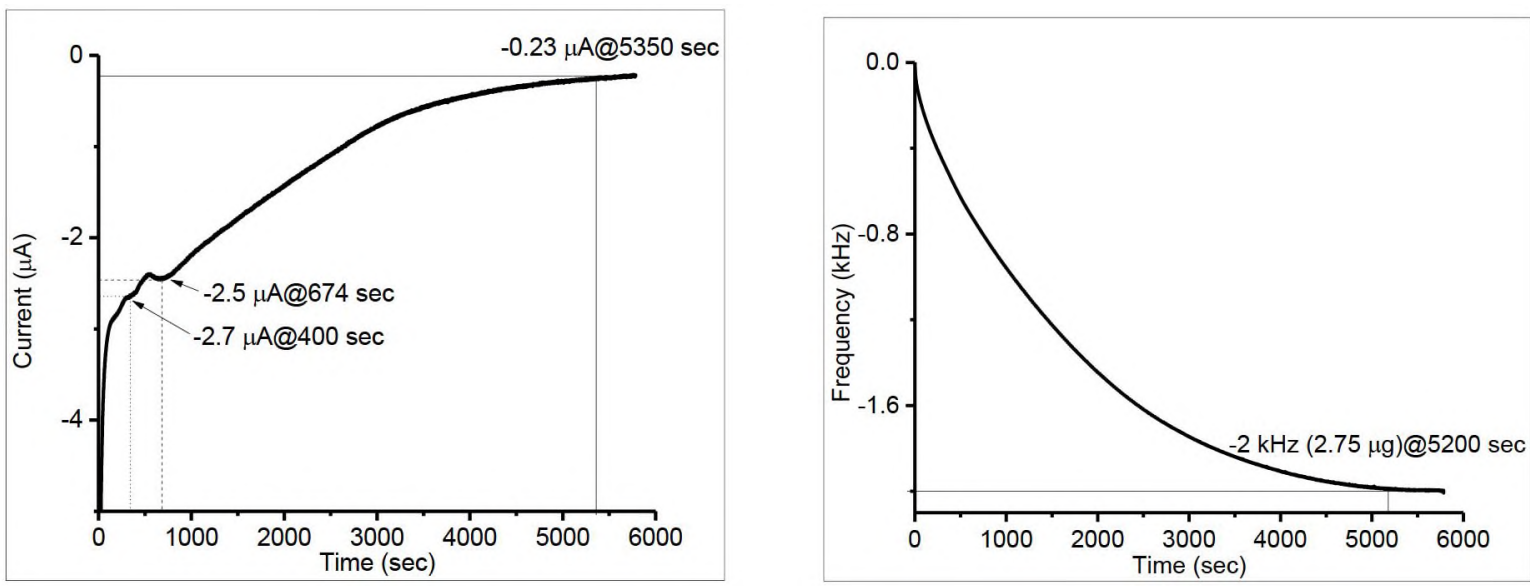

Figure 4. Amperometry-EQCM curves of electrodeposition process of DHI-melanin films 
The thickness of the synthetic melanin film has been estimated using EQCM in combination with the amperometric technique. Fig. 4 (left) shows the amperometry curve of DHI-melanin polymerization that started at about $-4 \mu \mathrm{A}$ and reached a plateau at $-0.23 \mu \mathrm{A}$ when applied a constant potential of $0.5 \mathrm{~V}$. The increase in anodic current has been recorded twice at currents of -2.7 and $-2.5 \mu \mathrm{A}$ at times of 400 and $674 \mathrm{sec}$, respectively. Those two current changes seem to be attributed to the formation of quinone and semiquinone, while after that the current continuously decreased until reaching a constant current value at $-0.23 \mu \mathrm{A}$ and time of $5350 \mathrm{sec}$. On the other side, Fig. 4 (right), the curve of the EQCM frequency vs. time has been established to determine the final frequency of the crystal after the DHI-melanin formation. It has been found that the calculated mass of polymerized melanin is $2.75 \mu \mathrm{g}$ at frequency of $-2 \mathrm{kHz}$ and total time of 5200 $\mathrm{sec}$. Furthermore, the melanin film thickness was calculated using the data collected from EQCM to be $23 \mathrm{~nm}$, which is fully consistent with Ball research group (24). It is also the optimum thickness that shows strong adhesion properties.
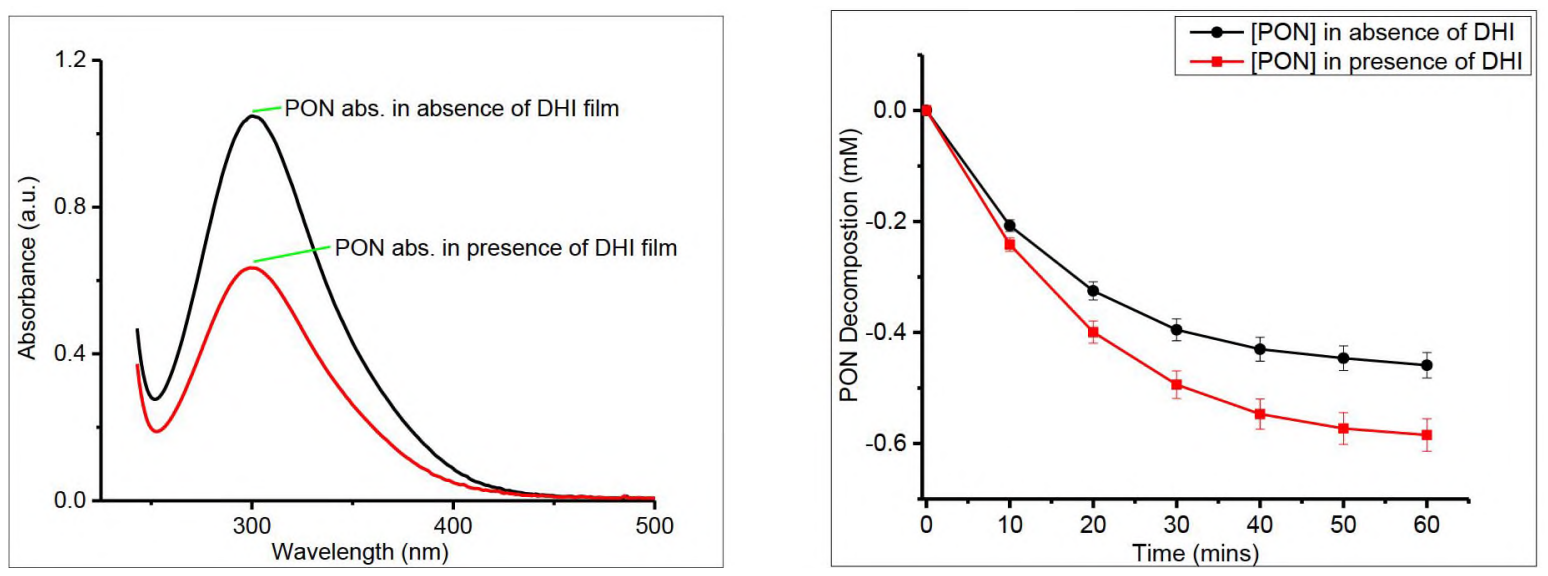

Figure 5. Absorbance changes of PON in presence and absence of DHI film and how it affects the decomposition rate of PON

Fig. 5 illustrates the UV-Vis absorption spectra of PON in the presence and absence of the DHImelanin films. The normal absorbance peak of PON at $302 \mathrm{~nm}$ exhibits a significant decrease in the absorbance, which reflects an increase in the decomposition of PON. Two sets of experiments were applied to study the change in the PON absorbance after exposure to the synthetic melanin film. The first set was performed using melanin coated $1 \mathrm{~cm}$ of the ITO slides using CV, and then immersed in a buffer solution of $\mathrm{pH} 9.5$ containing $10 \mu \mathrm{L}$ PON $(10 \mathrm{mM})$. On the other experimental set, we prepared a solution of melanin films in $\mathrm{NaOH}$ solution $(\mathrm{pH} 10.5)$ and then add few $\mu \mathrm{L}$ of this melanin solution to PBS ( $\mathrm{pH}$ 7.4), which injected with PON solution. The results of both experiments were almost the same, since the decomposition of PON dramatically increase in the presence of DHI-melanin film. 


\section{Conclusion}

Melanin is a natural pigment that has many physiological functions including scavenging highly reactive oxygen-nitrogen species. The interaction of PON on the DHI-melanin electropolymerized glassy carbon electrodes has been intensively studied and examined using a variety of physicochemical techniques. The synthetic melanin films have been examined as electrochemical interfaces to detect and quantify PON in solution. PON seems to react with DHImelanin film and modify its chemical and electrochemical responses. Cyclic voltammetry shows varying responses to addition of $\mathrm{PON}$, which allows the possibility to select low potential for amperometric detection of $0.5 \mathrm{~V}$ vs. $\mathrm{Ag} / \mathrm{AgCl}$. Absorbance spectroscopy confirms that the decomposition rates of PON significantly increase in the presence of DHI-melanin film whether coated ITO glass substrates or dissolved in $10 \% \mathrm{NaOH}(\mathrm{pH} \mathrm{10.5).} \mathrm{The} \mathrm{DHI-melanin} \mathrm{modified}$ electrodes have the potential to work as sacrificial sensors to detect PON at higher pHs (9.5).

\section{References}

1. Kollias, N.; Sayre, R. M.; Zeise, L.; Chedekel, M. R., Photoprotection by melanin. Journal of photochemistry and photobiology. B, Biology, 9(2), 135-60 (1991).

2. Costa, T. G.; Younger, R.; Poe, C.; Farmer, P. J.; Szpoganicz, B., Studies on Synthetic and Natural Melanin and Its Affinity for Fe(III) Ion. Bioinorganic Chemistry and Applications (2012). 3. Stępień, K.; Zajdel, A.; Wilczok, A.; Wilczok, T.; Grzelak, A.; Mateja, A.; Soszyński, M.; Bartosz, G., Dopamine-melanin protects against tyrosine nitration, tryptophan oxidation and $\mathrm{Ca}$ (2+)-ATPase inactivation induced by peroxynitrite. Biochimica et biophysica acta, 1523(2-3), 189-195 (2000).

4. Seagle, B. L.; Rezai, K. A.; Gasyna, E. M.; Kobori, Y.; Rezaei, K. A.; Norris, J. R., Jr., Time-resolved detection of melanin free radicals quenching reactive oxygen species. $J \mathrm{Am} \mathrm{Chem}$ Soc., 127(32), 11220-1 (2005).

5. Schraermeyer, U.; Heimann, K., Current understanding on the role of retinal pigment epithelium and its pigmentation. Pigment Cell \& Melanoma Research, 12(4), 219-236 (1999).

6. Akeo, K.; Amaki, S.; Suzuki, T.; Hiramitsu, T., Melanin Granules Prevent the Cytotoxic Effects of 1-DOPA on Retinal Pigment Epithelial Cells in Vitro by Regulation of NO and Superoxide Radicals. Pigment Cell \& Melanoma Research, 13(2), 80-88 (2000).

7. Sarna, T.; Plonka, P. M., Biophysical studies of melanin. In Biomedical EPR, Part A: Free Radicals, Metals, Medicine, and Physiology, pp 125-146, Springer (2005).

8. Meredith, P.; Sarna, T., The physical and chemical properties of eumelanin. Pigment Cell \& Melanoma Research, 19 (6), 572-594 (2006).

9. Fedorow, H.; Tribl, F.; Halliday, G.; Gerlach, M.; Riederer, P.; Double, K. L., Neuromelanin in human dopamine neurons: Comparison with peripheral melanins and relevance to Parkinson's disease. Progress in Neurobiology, 75(2), 109-124 (2005).

10. Subianto, S.; Will, G.; Meredith, P., Electrochemical synthesis of melanin free-standing films. Polymer, 46(25), $11505-11509$ (2005).

11. Ito, S.; Wakamatsu, K., Quantitative Analysis of Eumelanin and Pheomelanin in Humans, Mice, and Other Animals: a Comparative Review. Pigment Cell Research, 16(5), 523-531 (2003). 
12. Bayachou, M.; Altawallbeh, G.; Kalil, H.; Wojciechowski, S.; Bose, T., Methods of Peroxynitrite Synthesis in the Context of the Development and Validation of Peroxynitrite Sensors. In Peroxynitrite Detection in Biological Media, pp 48-62, Royal Chemical Society (2015).

13. Peteu, S. F.; Banihani, S.; Gunesekera, M. M.; Peiris, P.; Sicuia, O. A.; Bayachou, M., Peroxynitrite and Nitroxidative Stress: Detection Probes and Micro-Sensors. A Case of a Nanostructured Catalytic Film. In Oxidative Stress: Diagnostics, Prevention, and Therapy, pp 311 339, American Chemical Society (2011).

14. Dzierzega-Lecznar, A.; Stepien, K.; Chodurek, E.; Kurkiewicz, S.; Swiatkowska, L.; Wilczok, T., Pyrolysis-gas chromatography/mass spectrometry of peroxynitrite-treated melanins. Journal of Analytical and Applied Pyrolysis, 70(2), 457-467 (2003).

15. Stepień, K.; Wilczok, A.; Zajdel, A.; Dzierzega-Lecznar, A.; Wilczok, T., Peroxynitrite mediated linoleic acid oxidation and tyrosine nitration in the presence of synthetic neuromelanins. Acta Biochimica Polonica, 47(4), 931-940 (1999).

16. Lee, C. S.; Lee, C. S.; Ko, H. H.; Song, J. H.; Han, E. S., Effect of R-(-)-deprenyl and harmaline on dopamine- and peroxynitrite-induced membrane permeability transition in brain mitochondria. Neurochemical Research, 27(3), 215-224 (2002).

17. Padmaja, S.; Madison, S. A., Reaction of peroxynitrite with the melanin precursor, 5,6dihydroxyindole-2-carboxylic acid. Research on Chemical Intermediates, 25(5), 441-458 (1999).

18. Regoli, F.; Winston, G. W., Quantification of total oxidant scavenging capacity of antioxidants for peroxynitrite, peroxyl radicals, and hydroxyl radicals. Toxicology and Applied Pharmacology, 156(2), 96-105 (1999).

19. Liu, Y. L.; Ai, K. L.; Ji, X. Y.; Askhatova, D.; Du, R.; Lu, L. H.; Shi, J. J., Comprehensive Insights into the Multi-Antioxidative Mechanisms of Melanin Nanoparticles and Their Application To Protect Brain from Injury in Ischemic Stroke. Journal of the American Chemical Society, 139(2), 856-862 (2017).

20. Uppu, R. M., Synthesis of peroxynitrite using isoamyl nitrite and hydrogen peroxide in a homogeneous solvent system. Analytical Biochemistry, 354(2), 165-168 (2006).

21. Uppu, R. M.; Pryor, W. A., Synthesis of peroxynitrite in a two-phase system using isoamyl nitrite and hydrogen peroxide. Analytical Biochemistry, 236(2), 242-249 (1996).

22. Sauerbrey, G., Verwendung von Schwingquarzen zur Wägung dünner Schichten und zur Mikrowägung. Zeitschrift für Physik, 155(2), 206-222 (1959).

23. Bernsmann, F.; Ponche, A.; Ringwald, C.; Hemmerlé, J.; Raya, J.; Bechinger, B.; Voegel, J.-C.; Schaaf, P.; Ball, V., Characterization of Dopamine-Melanin Growth on Silicon Oxide. The Journal of Physical Chemistry C, 113(19), 8234-8242 (2009).

24. Bernsmann, F.; Voegel, J. C.; Ball, V., Different synthesis methods allow to tune the permeability and permselectivity of dopamine-melanin films to electrochemical probes. Electrochimica Acta, 56(11), 3914-3919 (2001).

25. Kim, I. G.; Nam, H. J.; Ahn, H. J.; Jung, D. Y., Electrochemical growth of synthetic melanin thin films by constant potential methods. Electrochimica Acta, 56(7), 2954-2959 (2011).

26. Salomäki, M.; Tupala, M.; Parviainen, T.; Leiro, J.; Karonen, M.; Lukkari, J., Preparation of Thin Melanin-Type Films by Surface-Controlled Oxidation. Langmuir, 32(16), 4103-4112 (2016).

27. Wunsche, J.; Rosei, F.; Graeff, C. F. O.; Santato, C., Growth and Morphology of Eumelanin Thin Films - A Future Bioelectronic Material? Bioelectronics, Biointerfaces, and Biomedical Applications 4, 35(7), 75-81 (2011). 
28. Costa, T. G.; Younger, R.; Poe, C.; Farmer, P. J.; Szpoganicz, B., Studies on Synthetic and Natural Melanin and Its Affinity for Fe(III) Ion. Bioinorganic Chemistry and Applications, 2012, $1-9$ (2012).

29. Gidanian, S.; Farmer, P. J., Redox behavior of melanins: direct electrochemistry of dihydroxyindole-melanin and its $\mathrm{Cu}$ and $\mathrm{Zn}$ adducts. Journal of Inorganic Biochemistry, 89(1-2), 54-60 (2002).

30. Meyskens, F.; Gidanian, S.; Farmer, P. J., Pro-oxidant properties of melanosomal melanin from melanoma origin. Free Radical Biology and Medicine, 41, S111-S111 (2006).

31. Meyskens, F. L.; Yang, S.; Farmer, P. J.; Anton-Culver, H.; Culver, D., Cobalt and copper are candidates as co-carcinogens in the pathogenesis of cutaneous melanoma. Journal of Investigative Dermatology, 127, S153-S153 (2007).

32. Szpoganicz, B.; Gidanian, S.; Kong, P.; Farmer, P., Metal binding by melanins: studies of colloidal dihydroxyindole-melanin, and its complexation by $\mathrm{Cu}(\mathrm{II})$ and $\mathrm{Zn}(\mathrm{H})$ ions. Journal of Inorganic Biochemistry, 89(1-2), 45-53 (2002).

33. Liu, Y.; Ai, K.; Liu, J.; Deng, M.; He, Y.; Lu, L., Dopamine-melanin colloidal nanospheres: an efficient near-infrared photothermal therapeutic agent for in vivo cancer therapy. Advanced materials, 25(9), 1353-1359 (2013). 